Article

\title{
Current Advancements of and Future Developments for Fourth Party Logistics in a Digital Future
}

\author{
Hans-Joachim Schramm ${ }^{1,2, *} \mathbb{0}$, Carolin Nicole Czaja ${ }^{1}$, Michael Dittrich ${ }^{3}$ and \\ Matthias Mentschel ${ }^{4}$ \\ 1 Department of Global Business and Trade, Institute for Transport and Logistics Management, \\ WU Wirtschaftsuniversität Wien, 1090 Wien, Austria; carolin.czaja@googlemail.com \\ 2 Department for Operations Management, Copenhagen Business School, 2000 Frederiksberg, Denmark \\ 3 Accenture Strategy—Supply Chain Management ASG, Accenture, 8001 Zürich, Switzerland; \\ Michael.Dittrich@accenture.com \\ 4 Accenture Strategy—Supply Chain Management ASG, Accenture, 80807 München, Germany; \\ Matthias.Mentschel@accenture.com \\ * Correspondence: hschramm@wu.ac.at; Tel.: +43-1-31336-5891
}

Received: 31 December 2018; Accepted: 4 February 2019; Published: 11 February 2019

\begin{abstract}
This paper aims to analyze the potential future of the 4PL concept based on expert opinions with special regard to the influence of digitalization coming with a disruptive trans-formation of supply chains. Service arrangements, provider capabilities and benefits resulting from a 4PL partnership are compared in current and future configurations. The research follows an explorative mixed methods approach with semi-structured interviews followed by an expert panel. This builds a basis for an online survey questionnaire to inquire on important future aspects for the $4 \mathrm{PL}$ concept by a sample of respondents from multinational companies. Our results show a clear trend away from simply organizing transportation and logistics activities towards the provision of an IT platform as well as further value-added service activities such as planning, analytics and monitoring. Along with this, IT capabilities appear to be an important differentiator for 4PL providers in the future. Moreover, relationships between 4PL providers and their clients become closer and more strategic, which leads to a customer valuing not only direct cost reductions but rather improvements resulting from optimized operations through superior analysis and planning functions.
\end{abstract}

Keywords: fourth-party logistics (4PL); digitalization; IT capabilities

\section{Introduction}

About 20 years ago, Andersen Consulting (now Accenture) coined a novel concept of logistics outsourcing called fourth party logistics (4PL) as a modern solution to supply chain challenges [1]. This is complementing third party logistics (3PL) well established in the industry today with 3PL providers (3PLP) offering a large variety of standardized solutions [2]. Hence, 4PL providers (4PLP) are usually regarded to serve as an almost asset-free integrator between its clients and 3PLPS for managing complex supply chains [1,3]. Although studies at the early stages expected a high growth of the 4PL concept until 2010 [4], it has only gained significant attention in recent years with increasing importance [5-11]. Moreover, authors like [12-17] vaguely proclaim further developments towards higher levels of fifth party logistics (5PL) or even more, which may be merely speculation than real trends observed.

However, there is an uprising trend of digitalization [18] coming along with a disruptive transformation of supply chains [19] and resulting in a change of product or service offering $[20,21]$ which impacts significantly how organizations manage their boundaries [22]. This offers new 
opportunities for 4PLPs to benefit from better technological abilities for integration arise as IT advancements have been always identified to be an important driver in upcoming outsourcing developments $[15,23]$ and an important success factor for 4PLPs [24]. Whereas the 4PL concept has been widely discussed in extant literature [7] and case studies from successful implementations are known (e.g., $[8,15,25-36])$, information on future configurations of the 4PL concept are rarely available and mainly focus on potential drivers for future development. This situation thrives to identify services future 4PLPs will offer along with benefits for their clients.

The aim of this paper is to explore current advancements of the 4PL concept in practice and make predictions about how future 4PL configurations may evolve under the influence of digitalization. More specifically, we look at three areas directed at analyzing the adoption of 4PL services in practice today as well as the 4PL concept of the future. They are 4PL solutions (i.e., services offered by 4PLPs), 4PL providers (i.e., market environment of 4PLPs), 4PL customer benefits (i.e., benefits arising from using 4PL services along with its drawbacks) which form a conceptual framework under a mixed methods research design further elaborated in Section 2. In Section 3, we discuss our empirical results in the light of extant 4PL literature for better understanding of the aspects mentioned. Following this, conclusions and limitations as well as topics for future research are provided in Section 4.

\section{Research Design}

Mangan et al. [37] point out the importance of using a combination of qualitative and quantitative methods in logistics research. Mixed methods approaches consequently allow for a sequential use of information to apply the results of one method for the design of another [38]. The methodology applied here is a sequential fully mixed methods design with a dominant status of the quantitative method [39] which can be briefly described as follows: exploratory qualitative methods in form of (1) semi-structured interviews, followed by (2) an expert panel were conducted in a discovery-oriented manner to reveal the direction and explicitly formulated research hypotheses for a latter quantitative part of the study in form of (3) a structured online survey.

\subsection{Semi-Structured Interviews}

Semi-structured interviews generally allow gathering new insights while leaving open room for participants to go into detail about their understanding of a concept but also allow interviewers to guide interviewees and ask further questions [40]. Accordingly, the setup in our study were one-hour telephone semi-structured interviews with a set of predetermined open-ended questions clustered into topics of $4 \mathrm{PL}$ solutions, 4PL providers and 4PL customer benefits today and in the future (see Figure 1).

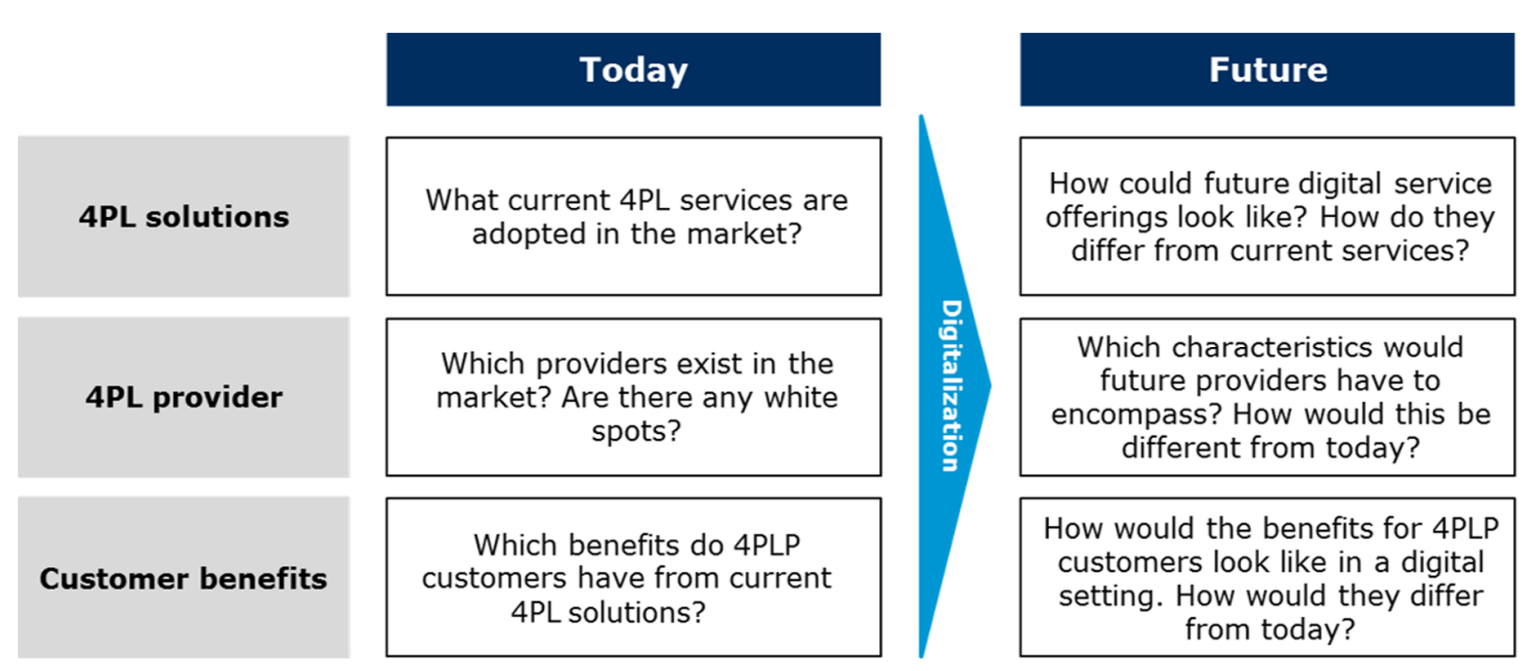

Figure 1. Overview of question frame for semi-structured interviews. 
Furthermore, purposeful sampling was applied to select suitable interview candidates for these semi-structured interviews. Accordingly, interviewees from multinational companies were selected based on their experience with the 4PL concept. In total, eleven interviews were conducted with four participants from the 4PL client's side; three from logistics service providers, three from IT providers and one from a consulting firm. While this number of participants is not very high, [38] argues that especially in a mixed methods setting, sample size of such a first qualitative study may be lower as it only should provide input for a subsequent quantitative study.

Results from these semi-structured interviews were analyzed based on the six-step approach by [41], as the goal of our analysis was to find supra-individual aspects and generate interpretive patterns. This procedure resulted in a theoretical generalization in which inferences from systematically analyzed patterns can be drawn. In the end, we obtained a set of observed aspects of the 4PL concept, which were further discussed in an expert panel to formulate explicit research hypotheses for the second part of the study.

\subsection{Expert Panel}

In the expert panel, results of our semi-structured interviews were presented in form of a workshop followed by an intensive discussion. As [40] pointed out, semi-structured group interviews (such as this expert panel), allow for gathering a large range of experiences, and are therefore specifically interesting for the purpose of reflection and verification. The expert panel consisted of four participants from the consulting company Accenture who have been working in the field of logistics consulting for many years. The sample can therefore be regarded as a convenience sample (cf. [42]). However, these experts have already participated in many business transformations and especially supported 4PL projects with different clients coming along with broad knowledge of current 4PL settings and market environments from various perspectives. The expert panel resulted in a further clarification on the possible future of the 4PL concept, a definition of future 4PL characteristics and a formulation of explicit research hypotheses for the second part of the study. Based on the results of the semi-structured interviews, information from literature as well as the knowledge of the experts, three research hypotheses evolved along with underlying constructs and factors to quantify them (see Table 1).

Table 1. Overview of research hypotheses, constructs and factors for the structured online survey.

\begin{tabular}{ccc}
\hline Hypothesis & Constructs & Factors \\
\hline RH1: 4PL Solutions & INT & INTISH, INTEIS, INTEIC, INTIIN \\
& EDA & EDAANA, EDAPLA, EDAMON \\
RH2: 4PL Providers & DIG & DIGPRO, DIGCOM, DIGAUT \\
& ITC & ITINFR, ITBUSP, ITPROA \\
RH3: 4PL Customer Benefits & SCC & SCCUNC, SCCDIV, SCCSIZ \\
& MSC & MSCUNC, MSCDIV, MSCSIZ \\
\hline
\end{tabular}

Our first research hypothesis targets future 4PL solutions and especially focuses on end-to-end supply chain integration which was an important aspect mentioned by participants in the semi-structured interviews. In the expert panel, aspects of integration or connectivity were intensively discussed because the participants agreed that providing this sort of 4PL service is a difficult endeavor. Moreover, it was argued that it is crucial that a supply chain is integrated before further 4PL services can be provided. This is because only through integration, information from different supply chain partners is combined and available for analysis in the first place. Consequently, the first research hypothesis was formulated as:

Research Hypothesis 1 (RH1). The ability to integrate supply chain partners will be the key success factor for future 4PLPs because it turns data into information and will drive all further 4 PL services like analytics, planning and monitoring. 
In other words, a 4PLP's service of integration (INT) provides the basis for other 4PL services (EDA), thus, integration positively influences their evolution. To measure this 4PL service of integration (INT), four factors were selected based on [43]. According to them, the 4PLP's ability to foster information sharing (INTISH), external integration of its client with suppliers (INTEIS) as well as customers (INTEIC) and the client's internal integration (INTIIN) are important factors that determine the performance of supply chain integration. While according to [43] information sharing measures the ability of information exchange between the company, its suppliers and customers, external integration with both customers and suppliers refers to the level of partnership and acknowledgement of external actors as part of the supply chain. Contrarily, they pointed out that internal integration refers to the cross-functional integration of internal functions. In this case, the integration of 4PLP with its client is measured because the service of integration is provided to the client. In terms of further services of effective data analysis (EDA), the factors analytics (EDAANA), planning (EDAPLA), and monitoring $(E D A M O N)$ activities were regarded. These services are in line with aspects frequently mentioned in the semi-structured interviews before. While planning and control activities as well as monitoring and reporting were mentioned as part of the current 4PL portfolio, analytics was one of the most mentioned aspects mentioned for the 4PL future.

Following Figure 1, our second research hypothesis deals then with future characteristics of 4PLPs. The most mentioned aspect for 4PLP capabilities seems to be IT competence. Furthermore, $90 \%$ of the interviewees considered digital technologies as one of the most important aspects for future 4PLPs, being able to provide and/or apply digital technologies highlights the importance of IT capabilities indicated by the participants of semi-structured interviews. The expert panel agreed with this notion and further argued that IT capabilities may be more difficult to achieve for players in the 4PL market than other capabilities. Moreover, this can be explained through an uprising trend of digitalization of the logistics industry, too, in which also connectivity plays an important role. Hence, to take into account the influence of digitalization on the restructuring of the 4PL market, the second research hypothesis is:

Research Hypothesis 2 (RH2). The rise of automation and digitalization will result in IT capabilities being the most important differentiating factor for future 4PLPs.

This implies that IT capabilities of 4PLPs (ITC) are positively influenced by an increasing adaption of automation and digitalization (DIG). The construct of digitalization (DIG) is broken down into three factors: digitalization of processes (DIGPRO), digitalization of communication (DIGCOM) as well as automation of processes (DIGAUT). The construct of IT competence of a 4PLP (ITC) includes then three factors according [44] focusing on three aspects that describe the IT capability of a company. First, IT capability includes a good IT infrastructure (ITINFR). This comprises of a standardized and integrated platform for accurate and effective information gathering and sharing. Secondly, IT business spanning capability is mentioned (ITBUSP) and this aspect focuses on the ability for business partnerships and synergies. Lastly, the factor of IT proactive stance (ITPROA) is addressed, which coins at the company using resources for new business opportunities and especially focuses on the company's ability to drive IT innovation.

Our third research hypothesis considers the customer benefits that arise from using a 4PL service. The aspect mentioned most in the semi-structured interviews were operational improvements together with improvements from enhanced IT and data analysis. Operational improvements can result from different services a 4PLP offers. The result of the expert panel was to focus on the area of supply chain complexity as the management of this complexity may result in distinct improvements in the client's operations. Scholars argued that a 4PL model can highly benefit a customer by reducing its logistics or supply chain complexity [24,45,46]. Moreover, Saglietto and Cézanne [7] found solving complex problems to be one of the main $4 \mathrm{PL}$ characteristics in their bibliometric analysis. This is why this 
research hypothesis focuses on the aspect of the 4PLP managing the client's complexity, thus resulting in benefits from reduced complexity for the client.

Research Hypothesis 3 (RH3). Customers will put a higher focus on service benefits of 4PL than on costs in the future because additional 4PL services become crucial to manage complex supply chains effectively.

It points to the fact that the higher the client's supply chain complexity (SCC), the more it values a 4PL service of managed supply chain complexity (MSC). Therefore, the influence on participants' perceptions of the complexity of their supply chain on the 4PL value creation by managing complexity in a supply chain was examined. To measure supply chain complexity (SCC), three factors suggested by [47] were used. One of these factors includes uncertainty in the supply chain (SCCUNC) which is related to lacking predictability or reliability of the supply chain. The factor of diversity (SCCDIV) targets both the multitude of products as well as supply chain partners (suppliers and customers) while size (SCCSIZ) is related to high product volumes or variety of activities [47]. Consequently, to quantify how a 4PLP may manage complexity (MSC), these three dimensions were rephrased in terms of 4PL services. Thus, the three factors used were managing uncertainty (MSCUNC), managing diversity (MSCDIV) as well as managing product volumes or variety of activities (MSCSIZ).

\subsection{Structured Online Survey}

In this final stage of our research design, a structured online questionnaire was used to draw inferences on the aforementioned three research hypotheses evolving from the course of the expert panel. This method was chosen to fit the needs of respondents of availability at their convenience and completion at a later stage [48]. To guarantee that all survey questions were understandable and the online questionnaire was technically working, a pretest was conducted.

The questionnaire itself consisted of a series of statements concerning the future of 4PLP in line with the constructs shown in Table 1. Therein, the participants were asked to choose the degree in percent to which they agreed with the mentioned statements with the help of a slider bar. In addition to this, several control variables were asked to put the data into context. To ensure a common understanding of the survey context, at the beginning, participants were informed about the definition of the future 4PLP as well as a definition for digitalization. In terms of sampling, we combined both sharpshooter and shotgun approaches as outlined by [49] to reach a maximum number of feedbacks within short time. First, personal and business contacts that are known experts in the field of 4PL were personally contacted in a sharpshooter approach. After a first invitation, follow-up emails were sent to known contacts in order to increase their response rate. To reach additional participants, the structured online survey was promoted via special interest groups in social networks like Facebook and LinkedIn and finally sent out to larger groups of experts via traditional mailing lists.

\section{Results and Discussion}

The online questionnaire was open for 39 days and a total of 34 respondents completed the survey. Out of these, no record had to be generally excluded. The questionnaire was accessed at a total of 73 times while most respondents that got beyond the introductory page, also finished the survey. Based on the total of 34 respondents, 14 considered to be potential 4 PL clients (41\%), 7 logistics service providers (21\%), 2 IT providers $(6 \%)$ and 11 firms providing consultancy services (32\%). Most respondents were from manufacturing $(29 \%)$ or transportation and storage $(21 \%)$ with the remainder spread over diverse sectors. Regarding firm size, $97 \%$ of the participants stated to work in companies with 1000 or more employees and only one person was from a company of less than 50 employees. Similarly, $91 \%$ of the companies featured annual sales revenues above $€ 250 \mathrm{~m}$, only two respondents answered to be from a company between $€ 50 \mathrm{~m}$ and $€ 250 \mathrm{~m}$ and one below $€ 50 \mathrm{~m}$. Thus, it can be concluded that almost all participants are from multinational companies located in the DACH region (i.e., Germany, Austria and Switzerland). Accordingly, a tendency towards European operations can 
be observed: 21 respondents named a responsibility for operations in Europe and 13 on a global level. Exactly $50 \%$ of the respondents work on an operational level or are team leader responsible for one to five other employees. The others follow higher degrees of seniority while $24 \%$ of the participants are managers responsible for more than 100 employees. Finally, most respondents work in operations departments (68\%). In the following, detailed results from the semi-structured interviews and structured online survey are presented including a comparison with extant literature for each of the three areas of 4PL solutions, 4PL providers and 4PL customer benefits as shown in Figure 1.

\subsection{PL Solutions}

Firstly, we aimed at assessing 4PL service configurations that are currently offered. To asses this question, both findings from the initial semi-structured interviews as well extant scholarly literature on the $4 \mathrm{PL}$ concept were combined.

Looking closer at the extant literature, 4PLPs are regarded to be foremost responsible for selecting suitable logistics service providers to enable the desired transport and logistics operations [50-52]. Moreover, 4PLPs are often associated with logistics planning and control activities. Win [52] argued that inventory management is one of the key $4 \mathrm{PL}$ activities. Warehouse management, inventory planning, forecasting activities, customs management, routing operations and network optimization are further activities performed by 4PLPs in this respect [23,32,52]. Additionally, 4PLPs are believed to have a consulting function and provide external expertise to their client company $[32,46,50]$. They provide such value-added services to the client depending on the companies' needs [31,53]. The 4PLP is also often said to be an intermediary and integrator, thus providing supply chain integration [32,54]. In this context, they provide a single interface for the client to communicate with the other actors [1].

Nonetheless, based on the findings of the semi-structured interviews, it can be argued that in practice, 4PL solutions mainly center around transport management and 3PL selection as these two aspects were mentioned by all interviewees (see left side of Figure 2). This also includes aspects such as service audits, customs management and ensuring that logistics operations run smoothly. Furthermore, five interviewees named services related to logistics planning and control activities like planning activities, forecasting and inventory control. Additional to these basic service offerings, further services are demanded by clients, most commonly classical logistics planning and control mechanisms similarly to the offerings of traditional 3PLPs. However, depending on the client's operations, as indicated by some interviewees, a 4PLP may be responsible for a greater set of activities because of the complexity of the client's operations.

\section{PL Solutions - Today}

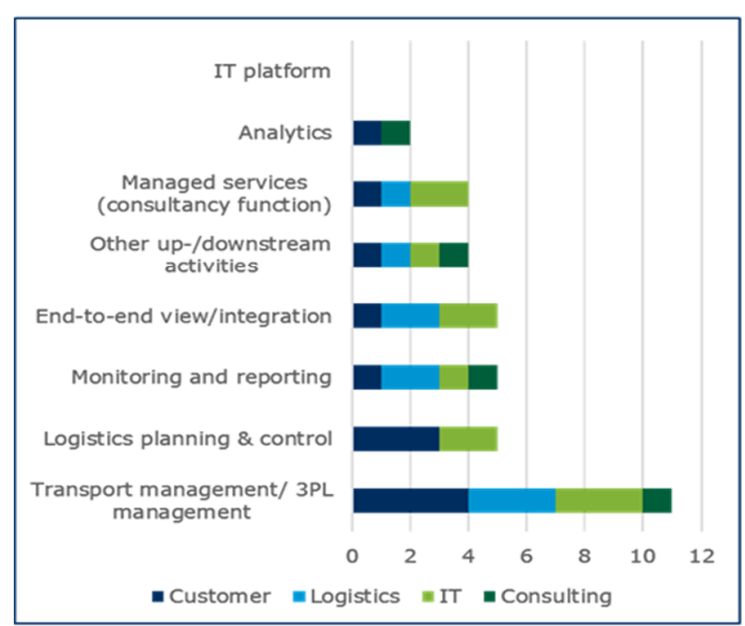

4PL Solutions - Future differences

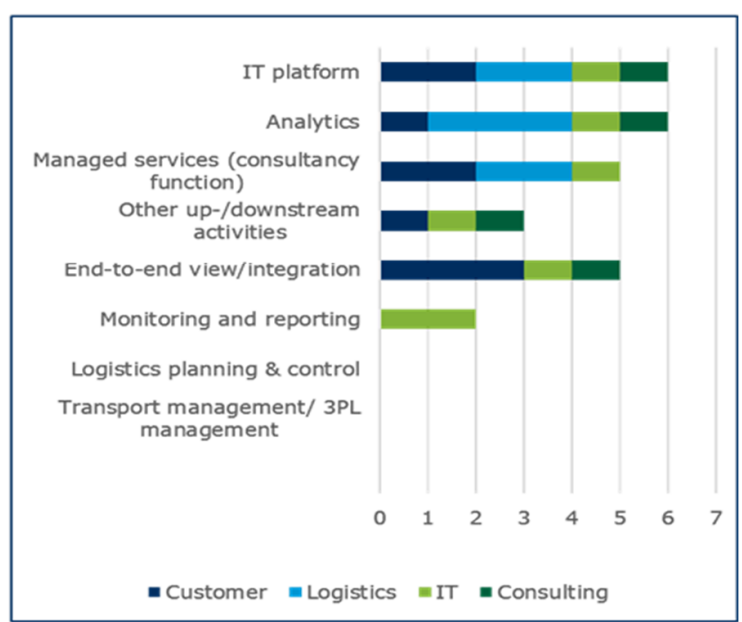

Figure 2. Comparison of 4PL solutions: results from semi-structured interviews. 
Compared with 4PL services as mentioned in extant literature, it is found that 4PL services mentioned generally correspond. Nevertheless, it is important to state that based on the first 4PL information, its general basic service offerings should reach beyond services 3PLPs usually offer. According to the 4PL concept definition, 4PL services offered should be driven by integrative activities and focus on managing complex supply chains. Even though these aspects are mentioned by the interviewees, they seem not to receive the same broad acceptance today as outlined in extant literature. For the interpretation of these findings, it should be kept in mind that all interviewees have had prior experience with the $4 \mathrm{PL}$ concept.

Consequently, based on these findings, it can be suggested that there is no standard 4PL service offering that finds agreement in practice except for basic transport and logistics management services. Furthermore, 4PL services can be manifold and specifically targeted at the client's needs with different degrees of responsibilities given to 4PLPs. While its personnel may be onsite working directly hand-in-hand with the client, in other settings orders would simply be exchanged by electronic means (for example EDI) to be executed by them.

Thereafter, the possible future for digital 4PL service configurations was examined. Therefore, results from the semi-structured interviews, the expert panel, as well as the structured online survey are jointly taken into account. Generally, there is a definite signal towards 4PLPs making an IT platform available (see right side of Figure 2). In the semi-structured interviews, providing an IT platform is one of the most-mentioned aspects in the future and in the online questionnaire, the issue whether a 4PLP has to provide an IT platform achieve high consent. Nonetheless, it is not defined whether the 4PLP itself is establishing and hosting such a platform or rather sources it from an external IT provider and then just supervises operations. In any case, it can be argued that having an effective IT platform may positively influence the integration of supply chain partners, especially because it enables information sharing. This is in line with [24] stating that by using IT systems effectively, transactional cost costs can be reduced by fostering co-operation and reducing complexity.

$4 \mathrm{PL}$ integrative service activities is another aspect that was further examined in the online questionnaire. There, the respondents supported the observation that a 4PLP will foster integration (see Table 2). The highest consent can be observed with the 4PL engaging in information sharing activities (INTISH). Nevertheless, importance could also lie in facilitating external integration of suppliers (INTEIS) and customers (INTEIC) as indicated before.

Table 2. Results concerning 4PL service of integration and 4PL effective data analysis.

\begin{tabular}{cccccccccc}
\hline $\begin{array}{c}\text { Respondent } \\
\text { Category }\end{array}$ & INT & INT & INT & INT & INT & $\begin{array}{c}\text { EDA } \\
\text { ANA }\end{array}$ & $\begin{array}{c}\text { EDA } \\
\text { PLA }\end{array}$ & $\begin{array}{c}\text { EDA } \\
\text { MON }\end{array}$ & EDA \\
\hline Customer & $55 \%$ & $72 \%$ & $67 \%$ & $76 \%$ & $68 \%$ & $73 \%$ & $71 \%$ & $78 \%$ & $73 \%$ \\
Logistics & $50 \%$ & $72 \%$ & $60 \%$ & $80 \%$ & $66 \%$ & $72 \%$ & $73 \%$ & $79 \%$ & $73 \%$ \\
IT Provider & $39 \%$ & - & $60 \%$ & - & $52 \%$ & $59 \%$ & $54 \%$ & $56 \%$ & $56 \%$ \\
Consulting & $55 \%$ & $71 \%$ & $67 \%$ & $82 \%$ & $68 \%$ & $80 \%$ & $76 \%$ & $78 \%$ & $80 \%$ \\
Total Average & $53 \%$ & $72 \%$ & $65 \%$ & $66 \%$ & $66 \%$ & $74 \%$ & $72 \%$ & $77 \%$ & $74 \%$ \\
\hline
\end{tabular}

On the contrary, the respondents are rather opposed to a 4PLP managing the companies' internal integration (INTIIN). This is in line with a low rate of agreement regarding the 4PLP taking care of the clients' IT infrastructure. Integrative and end-to-end solutions are also aspects pointed out in the semi-structured interviews as; however, the number of observations is higher for current than for future 4PL solutions (see Figure 2). Because the interviewees were asked about future differences, it is assumed that these aspects were simply not mentioned again.

Additionally, results from the structured online survey show that integration, and especially information sharing between the actors facilitated by the 4PLP positively influence its abilities to provide further 4PL services related to data analysis. Subsequent factor analysis with stepwise linear regression revealed positive effect of 4PL information sharing (INTISH) on 4PL monitoring (EDAMON), a positive influence of INTISH on 4PL analytics (EDAANA) and a positive influence of both INTISH 
and internal integration (INTIIN) on 4PL planning (EDAPLA) to be confirmed a (all highly statistically significant on a $5 \%$ level, see Appendix A). Overall, a strong positive linear influence of 4PL integration (INT) on 4PL data analysis (EDA) is obvious (Table 3). In conclusion, RH1 cannot be rejected because of a detected influence of 4PL integration (INT) on 4PL data analysis (EDA).

Table 3. Results from factor analysis of INT on EDA, DIG on ITC and SCC on MSC.

\begin{tabular}{cccccc}
\hline \multicolumn{1}{c}{ EDA } & \multicolumn{3}{c}{ ITC } & MSC \\
\hline Const. & $32.977(0.000)$ & Const. & $46.095(0.013)$ & Const. & $62.479(0.000)$ \\
INT & $0.617(0.000)$ & DIG & $0.333(0.130)$ & SCC & $0.165(0.525)$ \\
Adj. R & 0.642 & Adj. $\mathbf{R}^{2}$ & 0.044 & Adj. $\mathbf{R}^{2}$ & 0.014 \\
ANOVA & $\mathrm{F}=2.426(0.130)$ & ANOVA & $\mathrm{F}=2.476(0.130)$ & ANOVA & $\mathrm{F}=0.415(0.525)$ \\
\hline
\end{tabular}

Analytics, planning and monitoring activities are issues raised in both surveys. Based on the perceptions of the interviewees, planning and monitoring are activities existent in the current 4PL portfolio (see Figure 2). On the contrary, value-added services like analytics are almost mentioned for future 4PLPs. In the structured online survey, results show greatest consent of analytics with 4PLPs taking care of monitoring activities (see Table 2). Nonetheless, the agreement with 4PL analytics and planning services is comparably high.

Lastly, it should be noted that one of the major aspects pointed out in the semi-structured interviews is that partnership between 4PLPs and their clients are transferring from operational to more strategic relationships and simultaneously become closer. In the end, managing an effective partnership is the second most mentioned aspect for the future of the 4PL concept (see right side of Figure 2). This implies that $4 \mathrm{PL}$ providers do not only have to focus on presenting a good service portfolio but also need to bother about effectively managing their relationships with their clients ensuring trust.

Moreover, transport services should remain relevant in the future, it can be expected that the 4PL service portfolio will be enhanced with further offers like the provision of an IT platform and resulting possibilities for effective and efficient data analysis. These tools will especially encompass analytics, planning mechanisms as well as monitoring and reporting activities. Providing an IT platform has the potential to get a base product of $4 \mathrm{PL}$ services and according to the discussion in the expert panel, this could also be the chance for a company to become a provider of an industry-wide adopted IT platform.

\subsection{PL Providers}

This section points at the existing players in the market and possible white spots in the market. Because of a missing common understanding of 4PL concept, different taxonomies of 4PLPs have been suggested [23,32,52,55]. Razzaque and Chen Sheng [55] focused on the difference in an asset basis of the provider. Win [52] used these asset-basis criteria to differentiate between 3PL and 4PLPs and argues that there is a concern of 3PLPs offering 4PL services, because of their missing independency. Saglietto [32] identified four general categories of 4PLPs: (s1) 4PLPs that focus on document engineering activities, (s2) 4PLPs that develop integrated supply chain management software, (s3) 4PL subsidiaries of logistics groups with 3PL operations and (s4) pure 4PL players. While (s1) provide very dedicated services, (s2) offer both consultative skills of supply chain modeling and IT skills of infrastructure transformation, (s3) have their strength in offering global logistics solutions. While both entities may belong to logistics groups, they could be legally independent. Finally, (s4) combine different skills and rely on the expertise of their personnel so that they engage in consultative and IT related activities but are also knowledgeable in transport operations [32]. Pfohl et al. [23] identified four key players in their study: (p1) logistics system service providers, (p2) pure 4PL players, (p3) IT provider and (p4) consulting companies. Furthermore, they pointed out several advantages and disadvantages of these providers. Nevertheless, a comprehensive market report of 4PLPs in the DACH region similarly to [32] dealing with 4PLPs in France is virtually unknown to the authors. 
Based on the results from our semi-structured interviews, we could identify five distinct categories of 4PLPs, namely (c1) large logistics groups, (c2) pure 4PL players, (c3) niche logistics providers, and (c4) consultancies or (c5) technology providers. For the DACH region, especially the large logistics groups DHL, Kühne+Nagel, DB Schenker and Damco were mentioned. Furthermore, 4Flow (http://www.4flow.de/en.html) and 4PL Central Station (http://4plcs.com/en/) were explicitly named as pure 4PL players. For niche logistics players it was pointed out that they are supplying a very specific service. Accenture was regarded as a possible 4PLP from a consultancy perspective but no specific IT company was mentioned. No indications were made on the provider's market shares or positions in the market. Nevertheless, based on the frequency to which the actors were mentioned, indications can be made on the most well known actors. Notably, all 4PLPs labeled (c1) also offer 3PL and freight forwarding services and this again is in line with pre-existent relationships in a 3PL business area which may facilitate offering additional 4PL services, too [8,10,21,56-59]. Furthermore, it can be assumed that (c3) are operating in smaller, particularly specialized areas that may not be exposed to a great change. In sum, it appears that the large logistics groups heavily dominating the current 4PL market, making it especially useful for multinational companies to cooperate with them because of their global reach and well-known portfolio of services.

When it comes to the characteristics of future 4PLPs, inferences can be drawn on which companies may succeed in this 4PL market environment. Looking on results from both surveys (see Figure 3 and Table 4), it is obvious that IT competence of a 4PLP again plays an important role. As indicated in the previous section, especially providing an IT platform is a crucial future 4PL service. While the agreement for other areas of IT capabilities is lower, there is still a significant consent with the 4PLP being knowledgeable in IT business spanning activities and driving forward technological innovations. Consequently, the future 4PLP must possess own competence in the area of IT and may have choose to cooperate with a strong IT provider as technology partner if their own IT resources are not sufficient.

Table 4. Results concerning Digitalization and IT capability.

\begin{tabular}{ccccccccc}
\hline $\begin{array}{c}\text { Respondent } \\
\text { Category }\end{array}$ & $\begin{array}{c}\text { DIG } \\
\text { COM }\end{array}$ & $\begin{array}{c}\text { DIG } \\
\text { PRO }\end{array}$ & $\begin{array}{c}\text { DIG } \\
\text { AUT }\end{array}$ & DIG & $\begin{array}{c}\text { IT } \\
\text { INFR }\end{array}$ & $\begin{array}{c}\text { IT } \\
\text { BUSP }\end{array}$ & $\begin{array}{c}\text { IT } \\
\text { PROA }\end{array}$ & ITC \\
\hline Customer & $83 \%$ & $76 \%$ & $73 \%$ & $78 \%$ & $76 \%$ & $70 \%$ & $65 \%$ & $79 \%$ \\
Logistics & $80 \%$ & $82 \%$ & $77 \%$ & $79 \%$ & $77 \%$ & $79 \%$ & $71 \%$ & $76 \%$ \\
IT Provider & $87 \%$ & $91 \%$ & $90 \%$ & $89 \%$ & $57 \%$ & $34 \%$ & $69 \%$ & $53 \%$ \\
Consulting & $84 \%$ & $82 \%$ & $83 \%$ & $83 \%$ & $75 \%$ & $80 \%$ & $77 \%$ & $79 \%$ \\
Total Average & $83 \%$ & $80 \%$ & $78 \%$ & $80 \%$ & $75 \%$ & $73 \%$ & $70 \%$ & $73 \%$ \\
\hline
\end{tabular}

Concerning the structured online survey, it was expected that a 4PLP requires IT competence in the future because of the uprising trend of digitalization (see Table 4)—thus, digitalization (DIG) should have a positive influence on 4PL IT competence (ITC). However, factor analysis of both influence of DIG on ITC (see Table 3) as well as stepwise linear regression of factors of DIG on factors of ITC (see Appendix A) resulted in an overall low model fit including statistically non-significant factors. Consequently, RH2 has to be rejected so that a straightforward influence of digitalization on IT competence of 4PLPs cannot be confirmed. However, a closer look at the semi-structured interview results unveils further aspects apart from IT competence that may influence the success of the 4PLP positively (see Figure 3).

Because the 4PLP is considered to still be responsible for transport operations in the future, certain knowledge in logistics operations are a requirement. This fact that a stronger focus is laid on service activities and strategic operations, demanding service qualifications, is a clear indication of the importance of the 4PLP's consultative function with some interviewees arguing that he has to combine these different capabilities. Furthermore, drivers for choosing a 4PLP today such as the global reach of operations (see Figure 3) may also remain relevant in the future. Especially when working closely with the 4PLP, it may be beneficial for clients to have only a few 4PLPs that can take care of most of their businesses on a global scale. 
4PL Provider differentiation - Today

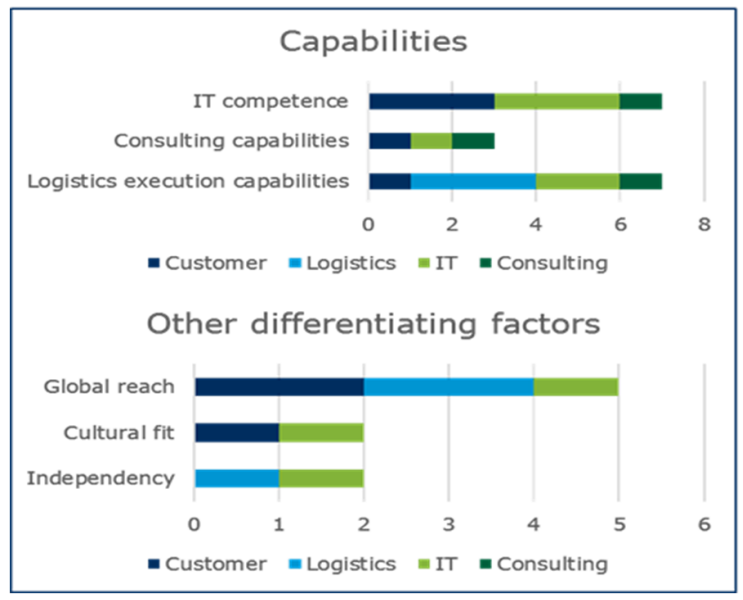

\section{PL Provider differentiation - Future}

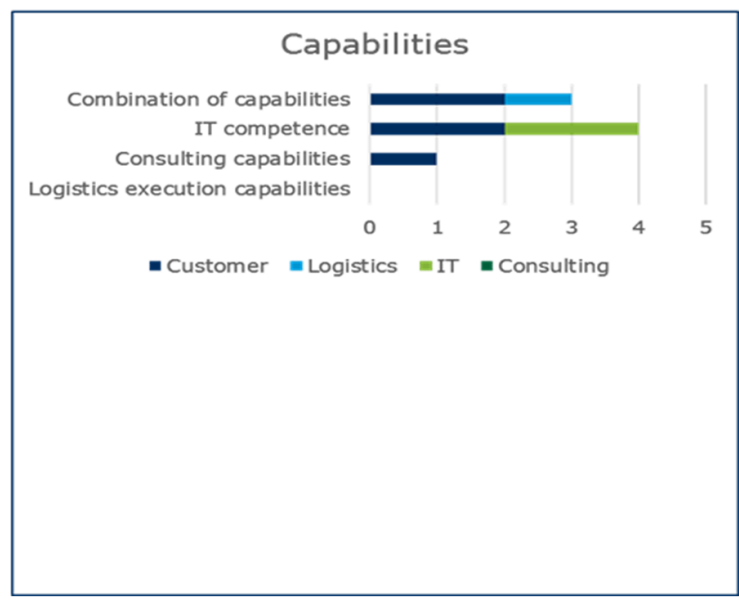

Figure 3. Comparison for 4PL provider differentiation: results of semi-structured interviews.

Consequently, it can be assumed that the providers' success is driven by their ability to adapt digital technologies and transfer the advantages to their client's businesses. As outlined by the participants of the semi-structured interviews and at the expert panel, it remains interesting to see which influence this trend has on larger logistics groups, since these may take longer to adapt to new technological solutions. Nevertheless, participants also argue that 4PL subsidiaries are becoming more independent from their entities, and may thus be able to faster react to change.

\subsection{PL Customer Benefits}

This section points at assessing the benefits from engaging in a 4PL relationship in a current setting. Looking at extant literature, [7] discussed that 4PL solutions are often applied to reduce logistics cost and direct cost savings can be achieved because a 4PLP is able to realize economies of scale and scope [51]. Further economic benefits may arise from improved operations [23] with 4PLPs may conduct logistics activities more effectively and efficiently, and thus achieve cost reductions [29]. Along with cost reduction, optimized operations may also result in improvements in the services offered to the customers [1] and better quality [23]. Furthermore, supply chain utilization could be increased significantly [60] and this may consequently increase revenue generated by the client [3]. 4PLPs may additionally support in decreasing supply chain complexity faced by companies $[7,24,45,46]$ and support with facing globalization challenges [61]. Moreover, 4PL clients have the possibility to focus on their core competencies and spend less time on non-core activities [1]. Moreover, 4PLPs provide valuable external expertise [7] and customers can benefit from an increased flexibility in their operations [23]. Additionally, Bade and Mueller [3] argue that using a 4PL service can result in a competitive advantage compared to rivals and consequently, competitiveness [62], and shareholder value could be increased [54].

Based on the findings from the semi-structured interviews, both operational improvements as well as direct cost savings were most frequently mentioned advantages (see Figure 4). Consequently, by cooperating with a 4PLP, a client can achieve directly observable cost reductions. Nonetheless, the interviewees also valued operational improvements a 4PLP brings about, as in the end, further cost decrease may reoccur and additionally, services can be improved. Furthermore, this aspect was actually pointed out more often than direct cost savings and certain interviewees argued that a 4PLP could only be successful when he creates value for the customer beyond directly reducing costs because these savings are most sustainable in the future. 
4PL Customer Benefits - Today

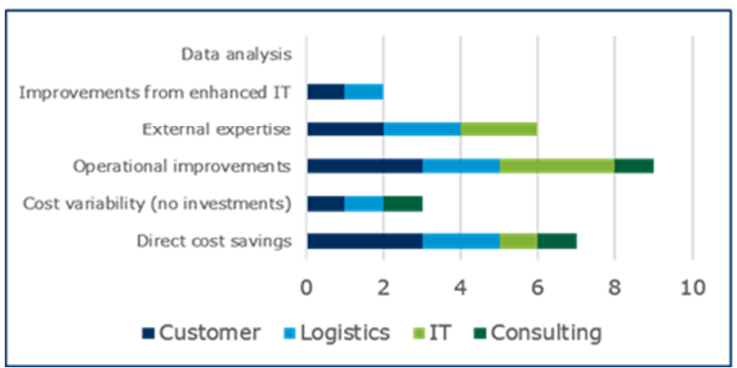

4PL Customer Benefits - Future

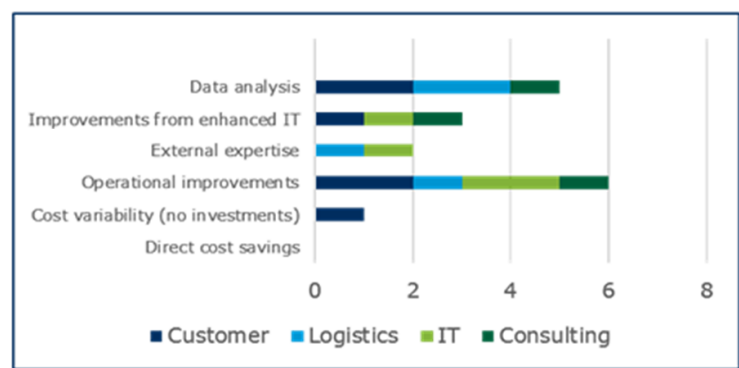

Figure 4. Comparison of 4PL customer benefits: results from semi-structured interviews.

Concerning the 4PL future, both surveys suggest that further service benefits may play a more prominent role in the future (see Figure 4 and Table 5). Based on our findings from the online questionnaire, managing, and thus reducing complexity is an important factor for future 4PLPs as they are supposed to manage diversity and higher product volumes and not only to support in reducing uncertainty (see Table 5). Furthermore, in the expert panel it was argued that there would be a higher amount of smaller transactions in the future that the 4PLPs can support with. This implies that a focus is put on $4 \mathrm{PL}$ management services rather than on simple executional tasks. By shifting towards more management services, a higher value is perceived by benefits that can be achieved through these activities.

Table 5. Results concerning supply chain complexity and managing supply chain complexity.

\begin{tabular}{ccccccccc}
\hline $\begin{array}{c}\text { Respondent } \\
\text { Category }\end{array}$ & SCC & SCC & SCC & \multirow{2}{*}{ SCC } & MSC & MSC & MSC & MSC \\
\hline Customer & $42 \%$ & $58 \%$ & $68 \%$ & $54 \%$ & $71 \%$ & $72 \%$ & $69 \%$ & $71 \%$ \\
Logistics & $44 \%$ & $67 \%$ & $64 \%$ & $59 \%$ & $77 \%$ & $71 \%$ & $69 \%$ & $72 \%$ \\
IT Provider & $69 \%$ & $87 \%$ & $74 \%$ & - & $74 \%$ & $65 \%$ & $76 \%$ & $72 \%$ \\
Consulting & $53 \%$ & $70 \%$ & $69 \%$ & $64 \%$ & $81 \%$ & $75 \%$ & $72 \%$ & $74 \%$ \\
Total Average & $47 \%$ & $65 \%$ & $68 \%$ & $59 \%$ & $75 \%$ & $72 \%$ & $70 \%$ & $72 \%$ \\
\hline
\end{tabular}

Factor analysis of both influence of supply chain complexity (SCC) on management of this complexity (MSC, see Table 3) as well as stepwise linear regression of factors of SCC on the factors of MSC (see Appendix A) resulted in an overall low model fit. Hence, a straightforward connection between supply chain complexity and its management by 4PLPs cannot be confirmed and so RH3 has to be rejected.

However, while conducting our semi-structured interviews it got also evident that 4PLPs are expected to create further benefits through data analysis resulting in optimized operations. This further backs up our former findings that there is a shift towards more service-oriented benefits. Additionally, it seems that less focus is put on direct cost savings because those were not explicitly mentioned. While cost savings might be important to be achieved as a baseline, it is certainly impossible to continuously drive down cost, for example, for transport activities. To achieve advantages beyond pure economies of scale in procurement, it might be required to optimize the entire transport operations.

Especially through additional benefits of visibility, transparency and flexibility, it may be possible to overcome risks that clients may fear of cooperating with a 4PLP. This may also result in the willingness to give the 4PLP more responsibility. Visibility and transparency could create further trust in their abilities and flexibility could allow for reducing the complexity resulting from cooperating with an outside provider. Through this, the 4PLP could regard more strategic issues instead of trying to achieve further direct cost cuttings in the operational areas. 
In conclusion, it can be noted that a shift away from a cost cutting perspective towards a more value-oriented angle can be expected for the 4PL future. 4PLPs would therefore have to focus on further advantages they can achieve rather than direct cost reduction means. This would also allow for great opportunities for the 4PLPs to engage in further fields of operations and reach the full potential of advantages that have been pointed out in extant 4PL literature. In the expert panel, it was also argued that benefits might further increase once a critical mass of partners has been achieved and the $4 \mathrm{PLP}$ is operating and optimizing an entire supply chain network.

\section{Conclusions}

This paper sheds light on the 4PL future and in particularly the role digitalization plays therein. In a mixed methods approach, findings from semi-structured interviews, followed by an expert panel and a structured online survey were combined to deduct future developments for the $4 \mathrm{PL}$ concept.

Findings from our initial semi-structured interviews clearly showed that the perception of current 4PL solutions deviates heavily from extant literature main interpretations of the 4PL concept. It appears that 4PL's main activities in practice today are quite similar to the service portfolio of 3PLs. This may stem from the fact that large logistics groups (c1) are the main 4PLP known to the interviewees. Whereas direct cost savings are an important aspect, they also focused on operational improvements a $4 \mathrm{PLP}$ can achieve. Consequently, there is potential for the 4PLP to extend its current offerings into more value-added service and IT driven areas.

Furthermore, it can be concluded that 4PL solutions of the future should consist of a well-functioning, cloud-based IT platform allowing seeming less communication, data exchange and subsequent analysis. Moreover, providing further value-added services such as analytics, planning and monitoring are particularly enabled by the integrative activities of a 4PLP. Fostering information sharing, in particular, may positively influence the provision of other, new sort of 4PL services, such as cloud logistics [63,64], crowd logistics [17,65-67] or super grid logistics [68]. With the help of effective big data analysis [69,70], the 4PLP can support its clients not only by enhancing operational efficiency, visibility and control over the supply chain, but by supporting new business opportunities through data-based intelligence services [68]. Certainly, this comes along with further responsibilities due to closer and more strategic relationships and, consequently, a 4PLP needs to engage in effective relationship management more than ever. However, the use of such a cloud-based IT platform together with integrated cross supply chain visibility capabilities results in a higher transparency of its operations and this again should make it easier for the client to trust its 4PLP. At the same time, complexity of integrating data exchange and communication could be reduced. Nevertheless, the 4PLP should have to prove its IT competence of operating such an IT platform but also drive forward innovations. Together with this, consultative strength may gain in importance when offering more such value-added services. Thereby, customer benefits will be enhanced from a focus on achieving directly observable cost reductions to long-term service benefits increasing the client's business performance.

Overall, our survey results together with the observed general willingness of cooperating with a $4 \mathrm{PLP}$ indicate a great potential for the 4PL concept to enlarge its current standing and offer further value-added services to the clients. For current 4PLPs in the market, it may become crucial to foster their IT competence either through choosing a strong cooperation partner or through improving their own competencies. A focus should especially lie on supplying an IT platform that allows for easy integration, data exchange and communication between the actors. Visibility and transparency should be encouraged by to achieve the client's trust. Moreover, the providers should improve their own abilities for planning, analytics and monitoring activities. Furthermore, clients should keep in mind that 4PLP's potential goes beyond achieving simple cost reductions when provided with the opportunities to engage in operations improvement. Therefore, they should be willing to pass on responsibility to the 4PLP in a close relationship that needs to be constantly nurtured.

However, since the focus was set on the 4PL concept, this research may neglect other possible trends encouraged by digitalization in the overall logistics service provider market environment as 
outlined by e.g., [68]. Nevertheless, in order to limit the scope of this study, the 4PL concept was chosen because of its aforementioned potential by many scholars and the 4PL concept's benefits from digitalization through e.g., facilitated integration by cloud-based IT platforms. Additionally, there are some limitations based on the method applied in this work. As for many qualitative methods, interpretation of the results is influenced by the researcher's subjective judgement. In this case, efforts were directed at preventing research bias by consulting an expert panel on the findings of the initial qualitative study. Moreover, it could be argued that there is a relatively low sample size for both studies, which may hinder a broad generalization of our findings. However, as the surveys targeted 4PL experts, a smaller sample size could also be tolerated because of a smaller population size whereas the total population and sampling frame is difficult to be determined.

This paper provides valuable insights into potential competencies a 4PLP may need in the future and benefits the customer will experience. While digitalization and supply chain complexity do not seem to account as sole factors influencing IT competence and supply chain management activities of a 4 PLP, a combination of these factors may drive change. Further research could focus on analyzing how these factors work together on changing the services portfolio that 4PLPs offer. Additionally, we saw that business background of both 4PLPs and their clients leads to different perceptions. For example, although IT providers are mentioned as potential 4PLPs, those included in our study rather argued that they would not enter into the 4PL business because it was not their core competence. However, they would be willing to cooperate with a 4PLP in supplying the IT environment. Another interesting direction of further research could point at examining whether there are significant differences in the perceptions of potential clients and their prospective 4PLPs.

Author Contributions: Conceptualization and methodology by all authors; investigation, formal analysis and original draft preparation by C.N.C. under supervision of H.J.S., M.D., M.M.; writing—review and editing by all authors.

Funding: This research received no external funding.

Conflicts of Interest: The authors declare no conflict of interest.

\section{Appendix A}

Table A1. Analysis for factors of 4PL Solutions constructs.

\begin{tabular}{|c|c|c|c|c|c|c|}
\hline & EDAANA & EDAPLA & EDAMON & EDAANA * & EDAPLA * & EDAMON * \\
\hline Const. & $\begin{array}{c}0.377 \\
(0.030)\end{array}$ & $\begin{array}{l}34.457 \\
(0.006)\end{array}$ & $\begin{array}{l}12.619 \\
(0.396)\end{array}$ & $\begin{array}{l}-5.199 \\
(0.648)\end{array}$ & $\begin{array}{l}35.466 \\
(0.001)\end{array}$ & $\begin{array}{c}8.254 \\
(0.406)\end{array}$ \\
\hline INTISH & $\begin{array}{c}0.832 \\
(0.000) \\
\end{array}$ & $\begin{array}{c}0.313 \\
(0.111)\end{array}$ & $\begin{array}{c}0.650 \\
(0.012)\end{array}$ & $\begin{array}{c}1.005 \\
(0.000)\end{array}$ & $\begin{array}{c}0.215 \\
(0.035) \\
\end{array}$ & $\begin{array}{c}0.882 \\
(0.000) \\
\end{array}$ \\
\hline INTEIS & $\begin{array}{l}-0.052 \\
(0.226)\end{array}$ & $\begin{array}{c}0.037 \\
(0.863)\end{array}$ & $\begin{array}{l}-0.016 \\
(0.986)\end{array}$ & - & - & - \\
\hline INTEIC & $\begin{array}{c}0.086 \\
(0.588)\end{array}$ & $\begin{array}{l}-0.023 \\
(0.865)\end{array}$ & $\begin{array}{c}0.229 \\
(0.197)\end{array}$ & - & - & - \\
\hline INTIIN & $\begin{array}{c}0.118 \\
(0.255)\end{array}$ & $\begin{array}{c}0.215 \\
(0.033)\end{array}$ & $\begin{array}{l}-0.016 \\
(0.961)\end{array}$ & - & $\begin{array}{c}0.215 \\
(0.005)\end{array}$ & - \\
\hline $\operatorname{Adj} . R^{2}$ & 0.628 & 0.433 & 0.472 & 0.621 & 0.476 & 0.642 \\
\hline ANOVA & $\begin{array}{c}\mathrm{F}=14.078 \\
(0.000)\end{array}$ & $\begin{array}{c}F=6.348 \\
(0.001)\end{array}$ & $\begin{array}{c}F=7.941 \\
(0.000)\end{array}$ & $\begin{array}{c}\mathrm{F}=51.861 \\
(0.000)\end{array}$ & $\begin{array}{c}\mathrm{F}=13.706 \\
(0.000)\end{array}$ & $\begin{array}{c}\mathrm{F}=52.001 \\
\quad(0.000)\end{array}$ \\
\hline
\end{tabular}


Table A2. Analysis for factors of 4PL Providers constructs.

\begin{tabular}{ccccc}
\hline & INTINFR & INTBUSP & INTPROA & INTINFR * \\
\hline \multirow{2}{*}{ Const. } & 42.526 & 63.899 & 57.693 & 34.572 \\
& $(0.043)$ & $(0.051)$ & $(0.033)$ & $(0.026)$ \\
\hline \multirow{2}{*}{ DIGPRO } & 0.656 & 0.622 & 0.086 & 0.500 \\
& $(0.013)$ & $(0.118)$ & $(0.788)$ & $(0.010)$ \\
\hline \multirow{2}{*}{ DIGCOM } & 0.020 & -0.250 & -0.418 & - \\
& $(0.948)$ & $(0.597)$ & $(0.286)$ & \\
\hline \multirow{2}{*}{ DIGAUT } & -0.284 & -0.259 & 0.517 & - \\
& $(0.245)$ & $(0.491)$ & $(0.102)$ & 0.175 \\
\hline \multirow{2}{*}{ Adj. $\mathbf{R}^{2}$} & 0.161 & 0.89 & 0.029 & $\mathrm{~F}=7.556$ \\
\multirow{2}{*}{ ANOVA } & $\mathrm{F}=2.977$ & $\mathrm{~F}=0.876$ & $\mathrm{~F}=1.302$ & $(0.100)$ \\
\hline
\end{tabular}

${ }^{*}$ step wise linear regression.

Table A3. Analysis for factors of 4PL Customer Benefits constructs.

\begin{tabular}{cccccc}
\hline & MSCUNC & MSCDIV & MSCSIZ & MSCUNC * & MSCSIZ $^{*}$ \\
\hline \multirow{2}{*}{ Const. } & 42.567 & 45.439 & 31.343 & 45.390 & 37.634 \\
& $(0.015)$ & $(0.008)$ & $(0.115)$ & $(0.002)$ & $(0.025)$ \\
\hline \multirow{2}{*}{ SCCUNC } & 0.174 & -0.014 & 0.001 & & - \\
& $(0.310)$ & $(0.933)$ & $(0.994)$ & & 0.501 \\
SCCDIV & 0.306 & 0.010 & 0.387 & 0.457 & $(0.044)$ \\
\hline \multirow{2}{*}{ SCCSIZ } & $(0.272)$ & $(0.971)$ & $(0.239)$ & $(0.034)$ & - \\
& 0.066 & 0.398 & 0.202 & - & 0.106 \\
\hline \multirow{2}{*}{ Adj. $\mathbf{R}^{\mathbf{2}}$} & $(0.812)$ & $(0.151)$ & $(0.541)$ & & $\mathrm{F}=4.440$ \\
\hline \multirow{2}{*}{ ANOVA } & 0.096 & 0.014 & 0.052 & 0.121 & $(0.044)$ \\
\hline
\end{tabular}

\section{References}

1. Gattorna, J. Strategic Supply Chain Alignment: Best Practice in Supply Chain Management; Gower Publishing Ltd.: Aldershot, UK, 1998.

2. Langley, N. 2016 Third-Party Logistics Study-The State of Logistics Outsourcing-Results and Findings from the 20th Annual Study. 2016. Available online: http://www.3plstudy.com/3pldownloads.php (accessed on 7 February 2019).

3. Bade, D.; Mueller, S. New for the millennium: 4PL. Transp. Distrib. 1999, 40, 78-80.

4. Frost \& Sullivan. Strategic Opportunities in Fourth Party Logistics. 2004. Available online: http://www. frost.com/prod/servlet/cpo/11194211 (accessed on 7 February 2019).

5. Bhatti, R.S.; Kumar, P.; Kumar, D. Integrated model for selection of third party service providers by global lead logistics providers. Int. J. Bus. Perform. Supply Chain Model. 2009, 1, 187-202. [CrossRef]

6. Seyed-Alagheband, S. 5 logistics parties. In Logistics Operations and Management: Concepts and Models; Farahani, R., Rezapour, S., Kardar, L., Eds.; Elsevier: London, UK, 2011; pp. 71-91.

7. Saglietto, L.; Cézanne, C. A bibliometric analysis of research on 4PL. Int. J. Transp. Econ. 2015, 42, 461-465.

8. Fulconis, F.; Nollet, J.; Paché, G. Purchasing of logistical services: A new view of LSPs' proactive strategies. Eur. Bus. Rev. 2016, 28, 449-466. [CrossRef]

9. Pavlić Skender, H.; Mirković, P.A.; Prudky, I. The role of the 4PL model in a contemporary supply chain. Pomorstvo 2017, 31, 96-101. [CrossRef]

10. Fattam, N.; Paché, G. 4PL intermediation: Exploring dimensions of social capital. In Global Intermediation and Logistics Service Providers; IGI Global: Pennsylvania, PA, USA, 2017; pp. 64-85. 
11. Fulconis, F.; Paché, G. Supply chain monitoring: LLPs and 4PL providers as orchestrators. Procedia Soc. Behav. Sci. 2018, 238, 9-18. [CrossRef]

12. Screeton, J. 5pls? The next supply chain innovation. Logist. Transp. Focus 2009, 2009, 30-34.

13. Vinay, V.; Kannan, G.; Sasikumar, P. Conceptual study on 3PL/4PL/new trends for service industry. Int. J. Serv. Technol. Manag. 2009, 12,3-22. [CrossRef]

14. Hill, B. Appeal of 4PL: Proliferation and differentiation as a 5PL. Logist. Transp. Focus 2011, 2011, 42-45.

15. Hosie, P.; Sundarakani, B.; Tan, A.W.K.; Koźlak, A. Determinants of fifth party logistics (5PL): Service providers for supply chain management. Int. J. Logist. Syst. Manag. 2012, 13, 287-316. [CrossRef]

16. Efremova, O.I.; Gabdullin, L.V. Logistic barter features as a new concept of supply chain management. Acad. Strat. Manag. J. 2016, 15, 19-25.

17. Gruchmann, T.; Melkonyan, A.; Krumme, K. Logistics business transformation for sustainability: Assessing the role of the lead sustainability service provider (6PL). Logistics 2018, 2, 25. [CrossRef]

18. Waller, M.A.; Fawcett, S.E. Data science, predictive analytics, and big data: A revolution that will transform supply chain design and management. J. Bus. Logist. 2013, 34, 77-84. [CrossRef]

19. Berman, S.J. Digital transformation: Opportunities to create new business models. Strat. Leadersh. 2012, 40, 16-24. [CrossRef]

20. Hess, T.; Matt, C.; Benlian, A.; Wiesböck, F. Options for formulating a digital transformation strategy. MIS Q. Exec. 2016, 15.

21. Hofmann, E.; Osterwalder, F. Third-party logistics providers in the digital age: Towards a new competitive arena? Logistics 2017, 1, 9. [CrossRef]

22. Fitzgerald, M.; Kruschwitz, N.; Bonnet, D.; Welch, M. Embracing digital technology: A new strategic imperative. MIT Sloan Manag. Rev. 2014, 55, 1-12.

23. Pfohl, H.-C.; Wagner, S.; Ries, A.; Berbner, U.; Witte, H. 4th Party Logistics-Chancen und Herausforderungen; Darmstadt Technical University: Darmstadt, Germany, 2014.

24. Bourlakis, C.; Bourlakis, M. Information technology safeguards, logistics asset specificity and fourth-party logistics network creation in the food retail chain. J. Bus. Ind. Mark. 2005, 20, 88-98. [CrossRef]

25. Bumstead, J.; Cannons, K. From 4PL to managed supply-chain operations. Logist. Transp. Focus 2002, 4, $18-24$.

26. Gattorna, J.; Ogulin, R.; Selen, W. An empirical investigation of 3rd- and 4th-party logistics provider practices in Australia. In Proceedings of the 2nd ANZAM Operations Management Symposium, Melbourne, Australia, 17-18 June 2004; pp. 1-19.

27. Krakovics, F.; Leal, J.E.; Mendes, P., Jr.; Santos, R.L. Defining and calibrating performance indicators of a $4 \mathrm{pl}$ in the chemical industry in Brazil. Int. J. Prod. Econ. 2008, 115, 502-514. [CrossRef]

28. Hsiao, H.I.; Kemp, R.; Van der Vorst, J.; Omta, S.O. A classification of logistic outsourcing levels and their impact on service performance: Evidence from the food processing industry. Int. J. Prod. Econ. 2010, 124, 75-86. [CrossRef]

29. Hingley, M.; Lindgreen, A.; Grant, D.B.; Kane, C. Using fourth-party logistics management to improve horizontal collaboration among grocery retailers. Supply Chain Manag. Int. J. 2011, 16, 316-327. [CrossRef]

30. Hingley, M.; Lindgreen, A.; Grant, D.B. Intermediaries in power-laden retail supply chains: An opportunity to improve buyer-supplier relationships and collaboration. Ind. Mark. Manag. 2015, 50, 78-84. [CrossRef]

31. Papadopoulou, E.; Manthou, V.; Vlachopoulou, M. 4PL network partnerships: The pre-selection phase. Int. J. Logist. Res. Appl. 2013, 16, 175-192. [CrossRef]

32. Saglietto, L. Towards a classification of fourth party logistics (4PL). Univ. J. Ind. Bus. Manag. 2013, 1, $104-116$.

33. Vivaldini, M.; Pires, S.R. Applying a business cell approach to fourth-party logistics freight management in the food service industry. Int. J. Logist. Res. Appl. 2013, 16, 296-310. [CrossRef]

34. Abidi, H.; De Leeuw, S.; Klumpp, M. The value of fourth-party logistics services in the humanitarian supply chain. J. Hum. Logist. Supply Chain Manag. 2015, 5, 35-60. [CrossRef]

35. Mehmann, J.; Teuteberg, F. Understanding the 4PL approach within an agricultural supply chain using matrix model and cross-case analysis. Int. J. Logist. Res. Appl. 2016, 19, 333-350. [CrossRef]

36. Dircksen, M.; Magnin, G. Evaluation of synergy potentials in transportation networks managed by a fourth party logistics provider. Transp. Res. Procedia 2017, 25, 824-841. [CrossRef]

37. Mangan, J.; Lalwani, C.; Gardner, B. Combining quantitative and qualitative methodologies in logistics research. Int. J. Phys. Distrib. Logist. Manag. 2004, 34, 565-578. [CrossRef] 
38. Morgan, D.L. Integrating Qualitative and Quantitative Methods: A Pragmatic Approach; Sage Publications: Thousand Oaks, CA, USA, 2013.

39. Leech, N.L.; Onwuegbuzie, A.J. A typology of mixed methods research designs. Qual. Q. 2009, 43, $265-275$. [CrossRef]

40. DiCicco-Bloom, B.; Crabtree, B.F. The qualitative research interview. Med. Educ. 2006, 40, 314-321. [CrossRef] [PubMed]

41. Meuser, M.; Nagel, U. Expertlnneninterviews-vielfach erprobt, wenig bedacht. In Qualitativ-Empirische Sozialforschung: Konzepte, Methoden, Analysen; Garz, D., Kraimer, K., Eds.; Westdt. Verlag: Opladen, Germany, 1991; pp. 441-471.

42. Patton, M.Q. Qualitative Evaluation and Research Methods; SAGE Publications: Thousand Oaks, CA, USA, 1990.

43. Zailani, S.; Rajagopal, P. Supply chain integration and performance: Us versus east asian companies. Supply Chain Manag. Int. J. 2005, 10, 379-393. [CrossRef]

44. Lu, Y.; Ramamurthy, K. Understanding the link between information technology capability and organizational agility: An empirical examination. MIS Q. 2011, 931-954. [CrossRef]

45. Lu, Q.; Meng, F.; Goh, M. Choice of supply chain governance: Self-managing or outsourcing? Int. J. Prod. Econ. 2014, 154, 32-38. [CrossRef]

46. Cézanne, C.; Saglietto, L. Redefining the boundaries of the firm: The role of 4PLs. Int. J. Logist. Manag. 2015, 26, 30-41. [CrossRef]

47. DeLeeuw, S.; Grotenhuis, R.; van Goor, A.R. Assessing complexity of supply chains: Evidence from wholesalers. Int. J. Oper. Prod. Manag. 2013, 33, 960-980. [CrossRef]

48. Dillman, D.A.; Smyth, J.D.; Melani, L. Internet, Mail, and Mixed-Mode Surveys: The Tailored Design Method; Wiley \& Sons: Toronto, ON, Canada, 2011.

49. Larson, P.D. A note on mail surveys and response rates in logistics research. J. Bus. Logist. 2005, 26, $211-222$. [CrossRef]

50. Stefansson, G. Collaborative logistics management and the role of third-party service providers. Int. J. Phys. Distrib. Logist. Manag. 2006, 36, 76-92. [CrossRef]

51. Fulconis, F.; Saglietto, L.; Paché, G. Strategy dynamics in the logistics industry: A transactional center perspective. Manag. Decis. 2007, 45, 104-117. [CrossRef]

52. Win, A. The value a 4PL provider can contribute to an organisation. Int. J. Phys. Distrib. Logist. Manag. 2008, 38, 674-684. [CrossRef]

53. Wang, X.; Persson, G.; Huemer, L. Logistics service providers and value creation through collaboration: A case study. Long Range Plan. 2016, 49, 117-128. [CrossRef]

54. Büyüközkan, G.; Feyzioğlu, O.; Ersoy, M.Ş. Evaluation of 4PL operating models: A decision making approach based on 2-additive choquet integral. Int. J. Prod. Econ. 2009, 121, 112-120. [CrossRef]

55. Razzaque, M.A.; Chen Sheng, C. Outsourcing of logistics functions: A literature survey. Int. J. Phys. Distrib. Logist. Manag. 1998, 28, 89-107. [CrossRef]

56. Hertz, S.; Alfredsson, M. Strategic development of third party logistics providers. Ind. Mark. Manag. 2003, 32, 139-149. [CrossRef]

57. Papadopoulou, E.; Manthou, V.; Vlachopoulou, M. Ocean carriers' transition from transport providers to supply chain integrators: A case study. Int. J. Shipp. Transp. Logist. 2009, 2, 76-94. [CrossRef]

58. Prockl, G.; Pflaum, A.; Kotzab, H. 3PL factories or lernstatts? Value-creation models for 3PL service providers. Int. J. Phys. Distrib. Logist. Manag. 2012, 42, 544-561. [CrossRef]

59. Multaharju, S.; Hallikas, J. Logistics service capabilities of logistics service provider. Int. J. Logist. Syst. Manag. 2015, 20, 103-121. [CrossRef]

60. Dutton, G. Supply chain integration-The rise of the 4PL-It takes more than strategy to implement supply chain optimization. World Trade 2009, 22, 20-23.

61. Fulconis, F.; Saglietto, L.; Paché, G. Exploring new competences in the logistics industry: The intermediation role of 4PL. Supply Chain Forum Int. J. 2006, 7, 68-77. [CrossRef]

62. Subramanian, N.; Gunasekaran, A.; Papadopoulos, T.; Nie, P. 4th party logistics service providers and industrial cluster competitiveness: Collaborative operational capabilities framework. Ind. Manag. Data Syst. 2016, 116, 1303-1330. [CrossRef]

63. Li, W.; Zhong, Y.; Wang, X.; Cao, Y. Resource virtualization and service selection in cloud logistics. J. Netw. Comput. Appl. 2013, 36, 1696-1704. [CrossRef] 
64. Subramanian, N.; Abdulrahman, M.D.; Zhou, X. Integration of logistics and cloud computing service providers: Cost and green benefits in the chinese context. Transp. Res. Part E Logist. Transp. Rev. 2014, 70, 86-98. [CrossRef]

65. Mladenow, A.; Bauer, C.; Strauss, C. "Crowd logistics": The contribution of social crowds in logistics activities. Int. J. Web Inf. Syst. 2016, 12, 379-396. [CrossRef]

66. Carbone, V.; Rouquet, A.; Roussat, C. The rise of crowd logistics: A new way to co-create logistics value. J. Bus. Logist. 2017, 38, 238-252. [CrossRef]

67. Carbone, V.; Rouquet, A.; Roussat, C. A typology of logistics at work in collaborative consumption. Int. J. Phys. Distrib. Logist. Manag. 2018, 48,570-585. [CrossRef]

68. DHL. DHL Logistics Trend Radar-Version 2018-19; DHL Trend Research: Troisdorf, Germany, 2018.

69. Wamba, S.F.; Akter, S.; Edwards, A.; Chopin, G.; Gnanzou, D. How 'big data'can make big impact: Findings from a systematic review and a longitudinal case study. Int. J. Prod. Econ. 2015, 165, 234-246. [CrossRef]

70. Wang, G.; Gunasekaran, A.; Ngai, E.W.; Papadopoulos, T. Big data analytics in logistics and supply chain management: Certain investigations for research and applications. Int. J. Prod. Econ. 2016, 176, 98-110. [CrossRef]

(C) 2019 by the authors. Licensee MDPI, Basel, Switzerland. This article is an open access article distributed under the terms and conditions of the Creative Commons Attribution (CC BY) license (http://creativecommons.org/licenses/by/4.0/). 